\title{
Educational disparities in health behaviors among patients with diabetes: the Translating Research Into Action for Diabetes (TRIAD) Study
}

\author{
Andrew J Karter*1,2, Mark R Stevens ${ }^{3}$, Arleen F Brown ${ }^{4}$, O Kenrik Duru ${ }^{4}$, \\ Edward W Gregg 3 , Tiffany L Gary ${ }^{5}$, Gloria L Beckles ${ }^{3}$, Chien-Wen Tseng6,7, \\ David G Marrero $^{8}$, Beth Waitzfelder ${ }^{6}$, William H Herman ${ }^{9}$, John D Piette ${ }^{10}$, \\ Monika M Safford ${ }^{11}$ and Susan L Ettner ${ }^{4}$
}

\begin{abstract}
Address: ${ }^{1}$ Division of Research, Kaiser Permanente, Oakland, CA, USA, ${ }^{2}$ Affiliate Professor, Dept. of Epidemiology, School of Public Health \& Community Health, University of Washington, USA, ${ }^{3}$ Centers for Disease Control and Prevention, Division of Diabetes Translation, Atlanta, GA, USA, ${ }^{4}$ Division of General Internal Medicine and Health Services Research, Department of Medicine, David Geffen School of Medicine at UCLA, Los Angeles, CA, USA, ${ }^{5}$ Department of Epidemiology, Johns Hopkins Bloomberg School of Public Health, Baltimore, MD, USA, ${ }^{6}$ Pacific Health Research Institute, Honolulu, HI, USA, 7 Dept. of Family Medicine and Community Health, University of Hawaii, Honolulu, HI, USA, ${ }^{8}$ Indiana University Diabetes Research and Training Center, Indianapolis, IN, USA, ${ }^{9}$ Div. of Metabolism, Endocrinology \& Diabetes, Dept. of Internal Medicine and Epidemiology, University of Michigan, Ann Arbor, MI, USA, ${ }^{10}$ Ann Arbor VAMC and University of Michigan, Ann Arbor, MI, USA and ${ }^{11}$ Deep South Center on Effectiveness at Birmingham VA Medical Center and Department of Preventive Medicine, University of Alabama at Birmingham, Birmingham, AL, USA

Email: Andrew J Karter* - andy.j.karter@kp.org; Mark R Stevens - zbd3@cdc.gov; Arleen F Brown - abrown@mednet.ucla.edu; O Kenrik Duru - kduru@mednet.ucla.edu; Edward W Gregg - edg7@cdc.gov; Tiffany L Gary - tgary@jhsph.edu; Gloria L Beckles - glb4@cdc.gov; Chien-Wen Tseng - cwtseng@hawaii.edu; David G Marrero - dgmarrer@iupui.edu; Beth Waitzfelder - bewaitzfelder@phrihawaii.org; William H Herman - wherman@umich.edu; John D Piette - jpiette@umich.edu; Monika M Safford - msafford@uab.edu;

Susan L Ettner - settner@mednet.ucla.edu

* Corresponding author
\end{abstract}

Published: 29 October 2007

BMC Public Health 2007, 7:308 doi:10.1 186/147/-2458-7-308

This article is available from: http://www.biomedcentral.com/I47/-2458/7/308

(C) 2007 Karter et al; licensee BioMed Central Ltd.

This is an Open Access article distributed under the terms of the Creative Commons Attribution License (http://creativecommons.org/licenses/by/2.0), which permits unrestricted use, distribution, and reproduction in any medium, provided the original work is properly cited.
Received: 31 August 2007

Accepted: 29 October 2007

\begin{abstract}
Background: Our understanding of social disparities in diabetes-related health behaviors is incomplete. The purpose of this study was to determine if having less education is associated with poorer diabetes-related health behaviors.

Methods: This observational study was based on a cohort of 8,763 survey respondents drawn from $\sim 180,000$ patients with diabetes receiving care from 68 provider groups in ten managed care health plans across the United States. Self-reported survey data included individual educational attainment ("education") and five diabetes self-care behaviors among individuals for whom the behavior would clearly be indicated: foot exams (among those with symptoms of peripheral neuropathy or a history of foot ulcers); self-monitoring of blood glucose (SMBG; among insulin users only); smoking; exercise; and certain diabetes-related health seeking behaviors (use of diabetes health education, website, or support group in last 12 months). Predicted probabilities were modeled at each level of self-reported educational attainment using hierarchical logistic regression models with random effects for clustering within health plans.
\end{abstract}

Results: Patients with less education had significantly lower predicted probabilities of being a nonsmoker and engaging in regular exercise and health-seeking behaviors, while SMBG and foot self- 
examination did not vary by education. Extensive adjustment for patient factors revealed no discernable confounding effect on the estimates or their significance, and most education-behavior relationships were similar across sex, race and other patient characteristics. The relationship between education and smoking varied significantly across age, with a strong inverse relationship in those aged 25-44, modest for those ages 45-64, but non-evident for those over 65 . Intensity of disease management by the health plan and provider communication did not alter the examined education-behavior relationships. Other measures of socioeconomic position yielded similar findings.

Conclusion: The relationship between educational attainment and health behaviors was modest in strength for most behaviors. Over the life course, the cumulative effect of reduced practice of multiple self-care behaviors among less educated patients may play an important part in shaping the social health gradient.

\section{Background}

Social disparities in health are well recognized, although the mechanisms that link lower socioeconomic status (SES) with poorer health outcomes are not fully understood [1,2]. Poorly educated, impoverished and minority patients often have poorer access to and lower quality of medical care $[3,4]$. However, social disparities in health have been reported even in populations with uniform access to care $[5,6]$, and thus alternative pathways should be considered. Educational attainment is the one aspect of SES which is usually established in early adulthood and stable over the life course, and is relatively easily ascertained. This paper focuses on educational disparities in diabetes-related health behaviors.

Unhealthy behaviors and psychological states (e.g., depression, hopelessness, anxiety) have been associated with poor childhood conditions, inadequate education, blue-collar employment and financial barriers [7]. Social epidemiologists Mirowsky and Ross have used the theory of human capital [8] to propose that education endows people with the means to become "effective" individuals, who gain control of their health by developing a healthy lifestyle, thus mediating the association between education and health. Moreover, effectiveness yields benefits that include prosperity (e.g., higher income among well educated) as well as social support, but also provides benefits that transcend both. The authors pose three ancillary hypotheses about how education promotes health [8]. The first hypothesis, the human capital theory of learned effectiveness, posits that education enables people to better merge otherwise unrelated behaviors into a unified healthy lifestyle [8]. Refutation of this theory requires that income fully mediates the education effect on health. The second hypothesis, the theory of personal control, posits that education facilitates a sense of control over one's life, and those who feel in control seek and act on information that may improve health [8]. The third hypothesis suggests that education-related family human capital is trans- mitted, i.e., educated parents inspire a healthy lifestyle in their offspring [8].

The associations between educational attainment and health behaviors are particularly important in diabetes, given the critical role of health behaviors, including diabetes self-management and health-related lifestyle [9-15]. Studies in diabetic populations with uniform access to and quality of care (receiving managed care or socialized medicine) have reported persistent social disparities in glycemic control $[16,17]$, diabetes-related comorbidites [18-20], and diabetes-related mortality [21], suggesting that factors other than health care access likely mediate the SES-diabetes health relationship. Using a sample of managed care patients with diabetes, we studied the crosssectional relationship between educational attainment (our primary measure of SES) and smoking, physical activity, self-monitoring of blood glucose (SMBG), foot self-exam, and diabetes-related health-seeking behaviors. We have previously shown that these managed care settings provide uniform access to and quality of diabetes care across levels of SES [6], providing less confounded data on the relationship between SES and health behaviors.

We hypothesized an educational gradient in health behaviors and that better quality of care and provider communication would attenuate the gradient. To elucidate possible mechanisms through which education may influence health behaviors, we structured analyses to evaluate (directly or indirectly) Mirowsky and Ross' hypotheses.

\section{Methods \\ Study Setting}

This research is part of the Translating Research Into Action for Diabetes (TRIAD) study, a multi-center cohort study examining individual, provider and health plan (i.e., structural) factors associated with diabetes care and outcomes. The TRIAD study was developed by and coor- 
dinated through six Translational Research Centers (TRCs) and the Centers for Disease Control and Prevention (CDC). The TRIAD TRCs collaborated with 68 provider groups in ten health plans that served approximately 180,000 patients with diabetes across seven states. We restricted the study to patients who spoke either English or Spanish. Patients from provider groups with fewer than 50 patients with diabetes were excluded. Participating health plans included staff model health maintenance organizations (HMOs), network/independent practice associations, point-of-service plans, and preferred provider organizations with commercial, Medicare, and Medicaid products. Thus the sample includes a diverse mix of patients including those enrolled through their employment, poor and elderly enrolled via federal programs, and individually enrolled patients. The Institutional Review Boards at each TRC and the CDC reviewed and approved the study protocol. TRCs initially enrolled randomly selected subjects between July 2000 and August 2001. The $\mathrm{CDC}$ and the National Institute for Health (NIH) funded the study. The design has been described in more detail previously [22].

\section{Study Design and Data Collection}

A standard algorithm was applied to automated pharmacy, laboratory, inpatient, and outpatient diagnostic data obtained from the participating health plans [23] to identify all community-dwelling diabetes patients 18 years and older who had been continuously enrolled for at least 18 months and could speak English or Spanish. The TRIAD study cohort was randomly selected from this population. Nursing home residents, pregnant women, and persons unable to provide informed consent were excluded. Of 13,086 contacted eligible people, 11,927 (91\% cooperation rate) responded to a first survey conducted in 2000-2001 (57\% of respondents by computer assisted telephone interview and $44 \%$ by written survey). A certified, back-translation of the survey was created for Spanish-speaking subjects and for these individuals, Spanish-speaking interviewers administered the interview over the phone. Using an algorithm endorsed by the Council of American Survey Research Organizations (CASRO), if persons unable to be contacted had the same rate of eligibility as those contacted, and were counted in the denominator, the survey response rate would have been $69 \%$. Following up on the 11,927 respondents to the first survey, we conducted a second survey in 2002-2003 and obtained $8,794(74 \%)$ responses via computerassisted telephone interview or mailed survey. After accounting for those lost to follow-up or no longer eligible for the study, the CASRO rate for the second cohort was $83 \%$. We used only this second cohort for the present study given many of our variables of interest were not included in the first survey. We further excluded 31 respondents age $<25$ years, as well as any respondents missing any exposures, outcomes or modeled covariates specific to this study to obtain our final study cohort of 8,763 patients.

\section{Exposures and outcomes}

Our primary exposure of interest was educational attainment (hereafter "education"), stratified into 4 levels: i) not a high school graduate, ii) high school graduate, but not college, iii) some college, or iv) 4-year college graduate or more. However, we also compared models specifying other measures of SES including annual family income, social class, and parental educational attainment. Social class was based on autonomy over one's labor in the workplace and was categorized through a modified Olin Wright classification [24]: 1) working class, 2) supervisory and 3) managerial (decision-making). The Olin Wright social classification is based on employment status and is widely used in European social research. Homemakers were considered "working class" unless they indicated otherwise. Respondents who were students, unemployed or retired, had never worked or who did not classify their past work were excluded from analysis of social class. Parental educational attainment was categorized by the educational level of the parent with the highest level of education.

Our outcomes of interest included dichotomized selfreported health behaviors among individuals for whom the behavior would be considered to have clear benefit, would be consistently recommended by their health care providers, and answered the relevant survey item. These outcomes included 1) daily self-monitoring of blood glucose among insulin-treated patients only ("SMBG"); 2) daily self-examination of feet among patients who reported any symptoms of peripheral neuropathy including decreased sensation of hot or cold, numbness, tingling or burning, a history of foot ulcers or previous amputation (if one foot); 3) current smoking; 4) regular exercise (= 10 minutes of walking daily and/or moderate leisure time physical activity on a regular basis); and 5) diabetesrelated health-seeking behavior including reported use of non-clinical services in past 12 months (diabetes website, support group, or health education) ("health-seeking"). Analysis of SMBG, foot exam, smoking, exercise and health-seeking was based, respectively, on the 1,912, $2,542,6,538,6,318$ and 6,290 eligible patients.

\section{Statistical analysis}

We used hierarchical logistic regression models (SAS GLIMMIX Macro with penalized quasi-likelihood estimation method), with random intercepts for health plan, to account for the clustered study design (health plan, provider group, and patient levels) and dependency of patient characteristics within health plans and provider groups. When outcomes are common, logistic regression 
odds ratios poorly approximate relative risk [25]; therefore we modeled predicted probabilities for each level of education, with observed margins for case-mix adjusters, rather than relying on odds ratios.

We present model estimates of the effect of each level of education adjusted for observed marginal distributions of characteristics that might confound the relationship between education and behavior: demographics (sex, age, race or ethnicity), severity measures (diabetes treatment, comorbidity score, duration of diabetes), depressive symptoms and employment status. For SMBG, we also adjusted of coverage for the costs of the test strips given the potential that this may confound the relationship with the social exposure and utilization. Refutation of Mirowsky and Ross's human capital theory of learned effectiveness [8] required that income fully mediate the education effect on health. Therefore we specified an additional set of models (one for each health behavior) that simultaneously adjusted for education and income. We also present results from models using alternative measures of SES (annual income, social class and parental education).

We summarized health behaviors using a count of the number of the studied beneficial behaviors each subject reported. For non-insulin treated patients, there were 4 possible self-care behaviors: 1) not smoking; 2) regular exercise; 3) daily foot exam; 4) health seeking behavior; and a fifth for insulin-treated patients only, 5) daily SMBG. Counts by level of education were estimated from hierarchical regression models accounting for clustering within health plans as a random effect, and using least square means with observed margins for case-mix adjusters listed above.

We also tested interactions between education and five hypothesized effect modifiers: age, sex, race/ethnicity, provider's communication skills (based on patient reports of their provider's ability to listen, explain, respect and spend time with patient), and disease management intensity. Provider communication and disease management intensity were scored and dichotomized (above/below the median based on factor analyses conducted in TRIAD [26]). We assessed whether any of these five potential effect modifiers interacted with education or any other SES measures (i.e., twenty cross-products) in separate models for each of the five behaviors (e.g., did the relationship between education and smoking differ for younger versus older patients).

\section{Results Population Characteristics}

The study population of 8,763 diabetic patients was racially diverse ( $56 \%$ non-white) and $90 \%$ of participants were older than 45 years of age (Table 1). About one quarter of the patients had annual household income under $\$ 15,000$ and $21 \%$ had not graduated high school. Only two percent of patients conducted the interview in Spanish. Most patients were treated with oral agents, insulin monotherapy or insulin combination therapy; only $7 \%$ controlled their diabetes with diet and exercise alone. At least one quarter of our subjects had a history of myocardial infarct (MI), coronary artery bypass graft (CABG), percutaneous transluminal coronary angioplasty (PTCA), stroke, or amputation.

\section{Association of education with health behaviors}

Predicted probabilities (95\% CI) of being a non-smoker or engaging in regular exercise and health-seeking behavior were significantly $(\mathrm{p}<0.001)$ lower among those with less education (Table 2). However, SMBG and foot exam were not significantly associated with educational attainment. Further, these relationships were not substantively altered by adjustment for demographics (sex, age, race or ethnicity), severity measures (diabetes treatment, comorbidity score, duration of diabetes), depressive symptoms, and employment status. In models adjusted for both income and education, educational gradients remained significant for smoking and health seeking behavior, while exercise became non-significant $(\mathrm{p}=0.08)$ (Table 3).

\section{Alternative measures of SES}

With few exceptions, the other SES indicators were similarly associated with behaviors. Similar to lower educational attainment, lower income was also significantly associated with higher rates of smoking, and lower rates of regular exercise and health-seeking behavior. The Olin Wright social class indicator suggested that being a worker (as opposed to supervisor or manager) was weakly associated with less exercise and health-seeking behavior, but was not associated with smoking, SMBG or foot exam. Lower parental educational attainment was also significantly associated less exercise and health-seeking behavior.

\section{Potential effect modifiers}

Contrary to our expectations, quality of care and provider communication did not significantly alter the observed education-behavior relationship, nor the relationships between the other SES measures and health behaviors. Also, these relationships were similar across sex, race and other patient characteristics. The notable exception was the relationship between education and smoking which varied significantly ( $p=0.003)$ across age, with a strong, inverse relationship in those aged 25-44, modest for those ages 45-64, and non-evident for those over 65 [27]. 
Table I: Subject characteristics, quality of care, provider communications, and out-of-pocket charges for the TRIAD study respondents $(n=8,763)^{*}$

\begin{tabular}{|c|c|c|}
\hline Subject characteristics & & $\mathbf{N}(\%)$ \\
\hline \multirow[t]{2}{*}{ Sex } & Women & $4687(53.5)$ \\
\hline & Men & $4076(46.5)$ \\
\hline \multirow[t]{3}{*}{ Age } & $25-44$ & $816(9.3)$ \\
\hline & $45-64$ & $4252(48.6)$ \\
\hline & 65 or older & $3684(42.1)$ \\
\hline \multirow[t]{5}{*}{ Race or Ethnicity } & Latino & $129 \mid(15.8)$ \\
\hline & Black, non-Latino & $1260(15.4)$ \\
\hline & White, non-Latino & $3594(44.0)$ \\
\hline & Asian/Pacific Islander & $1304(16.0)$ \\
\hline & Other & $720(8.8)$ \\
\hline \multirow[t]{4}{*}{ Annual Household Income } & $<\$ 15,000$ & $2017(24.3)$ \\
\hline & $\$ 15,001-40,000$ & $2783(33.6)$ \\
\hline & $\$ 40,001-75,000$ & $2066(24.9)$ \\
\hline & $>\$ 75,000$ & $1424(17.1)$ \\
\hline \multirow[t]{4}{*}{ Education } & Less than high school graduate & $1773(20.8)$ \\
\hline & High school graduate & $2530(29.7)$ \\
\hline & Some college & $2496(29.3)$ \\
\hline & College graduate & $1720(20.2)$ \\
\hline \multirow[t]{3}{*}{ Diabetes treatment } & Diet and exercise only & $604(7.0)$ \\
\hline & Oral agents only & $5215(60.0)$ \\
\hline & Insulin alone or in combination & $2868(33.0)$ \\
\hline \multirow[t]{2}{*}{ Comorbidity Score** } & No history of serious events & $6017(73.5)$ \\
\hline & History of one or more serious events & $2166(26.5)$ \\
\hline \multirow[t]{6}{*}{ Health plan location } & California & $|77|(20.2)$ \\
\hline & Hawaii & $2023(23.1)$ \\
\hline & Indiana & $904(10.3)$ \\
\hline & Michigan & $1268(14.5)$ \\
\hline & New Jersey & $1259(14.4)$ \\
\hline & Texas & $1538(17.6)$ \\
\hline
\end{tabular}

*Complete data only

**Summary score based on whether or not there is a history of myocardial infarct, CABG, PTCA, stroke, or amputation

\section{Summary measure of healthy behaviors}

The summary estimate of the total number of healthy behaviors reported by level of education is shown separately for insulin and non-insulin treated patients (Figure 1). In both cases, there was a significant relationship between education and the number of healthy behaviors (both $\mathrm{p}<0.001$ ).

\section{Discussion}

This is the first large study of the relationship between educational attainment and multiple health behaviors among fully insured patients enrolled in a managed care setting. We found that even in managed care settings with uniform access to and quality of diabetes care across levels of SES [6], less education was associated with poorer health care behaviors among particularly high risk patients for whom these behaviors would be unquestionably indicated and recommended by their health care providers.
Alternative SES indicators yielded similar, although not always significant, findings. In general, education and income more strongly predicted health behaviors than social class or parental education. Each indicator has characteristics which influence its association with each outcome. Income varies over time and is likely to be influenced by adult health status, since progressing disease severity may reduce income. Educational attainment, on the other hand, is generally more stable over the life course, and less likely to be influenced by diabetes health status, since diabetes related complications typically occur later in the life course. Moreover, since education is a strong predictor of subsequent income, income may be considered as on the causal pathway between education and behaviors. Parental education may be less predictive of adult behavior given that childhood social exposures may be overshadowed by later life experiences and opportunities for social advancement. The Olin Wright social classification was only weakly associated with health behaviors in this study. This measure of social stratification is questionable among homemakers and the unem- 
Table 2: Model-based* predicted probability estimates ( $95 \%$ confidence intervals) for self-reported health behaviors across levels of educational attainment, income, social class and parental educational attainment. Translating Research Into Action (TRIAD) Study.

\begin{tabular}{|c|c|c|c|c|c|}
\hline Socioeconomic Indicator & Smoking (\%) & $\begin{array}{c}\text { Regular } \\
\text { exercise (\%) }\end{array}$ & $\begin{array}{c}\text { Daily foot } \\
\text { self-exam (\%) }\end{array}$ & $\begin{array}{l}\text { Health-seeking } \\
\text { behavior (\%) }\end{array}$ & Daily SMBG† (\%) \\
\hline \multicolumn{6}{|l|}{ Educational attainment } \\
\hline Less than High School graduate & $24.0(20.8-27.5)$ & $41.9(37.2-46.7)$ & $70.8(65.6-75.4)$ & $20.8(16.9-25.3)$ & $71.6(62.4-79.3)$ \\
\hline High School graduate & $17.9(15.8-20.2)$ & $43.4(39.2-47.7)$ & $65.7(61.3-69.9)$ & $23.8(19.9-28.2)$ & $72.8(66.3-78.4)$ \\
\hline Some college/trade school & $17.6(15.6-19.8)$ & $48.4(44.1-52.7)$ & $68.7(64.4-72.6)$ & $30.1(25.6-35.0)$ & $77.7(72.2-82.5)$ \\
\hline College graduate & $10.4(8.6-12.4)$ & $50.2(45.6-54.8)$ & $67.3(61.9-72.3)$ & $33.1(28.2-38.5)$ & $77.1(71.0-82.3)$ \\
\hline $\mathrm{p}$-value & $<0.0001$ & 0.0001 & 0.3 & $<0.0001$ & 0.4 \\
\hline \multicolumn{6}{|l|}{ Income } \\
\hline$<\$ 15 \mathrm{~K}$ & $22.8(19.6-26.4)$ & $36.0(31.7-40.6)$ & $68.3(62.2-73.8)$ & $20.8(17.1-25.1)$ & $75.1(66.3-82.2)$ \\
\hline$\$ 15 K-\$ 40 K$ & $19.3(\mid 7.0-21.7)$ & $44.4(40.3-48.6)$ & $66.8(61.3-71.9)$ & $26.0(22.1-30.4)$ & $74.9(69.1-79.8)$ \\
\hline$\$ 40 \mathrm{~K}-\$ 75 \mathrm{~K}$ & $15.3(13.2-17.6)$ & $49.7(45.4-54.1)$ & $66.7(60.5-72.3)$ & $27.7(23.5-32.4)$ & $71.9(65.5-77.6)$ \\
\hline$>\$ 75 \mathrm{~K}$ & $11.4(9.4-13.8)$ & $56.0(51.2-60.8)$ & $63.9(56.5-70.7)$ & $31.4(26.5-36.7)$ & $79.2(72.3-84.7)$ \\
\hline $\mathrm{p}$-value & $<0.0001$ & $<0.0001$ & 0.7 & $<0.0001$ & 0.4 \\
\hline \multicolumn{6}{|c|}{ Employment-based social class§ } \\
\hline Worker & $17.3(15.2-19.6)$ & $41.6(38.1-45.2)$ & $66.6(62.4-70.6)$ & $23.9(20.0-28.3)$ & $78.2(73.1-82.6)$ \\
\hline Supervisor & $17.5(\mid 4.7-20.6)$ & $46.0(41.7-50.3)$ & $70.3(64.8-75.2)$ & $25.3(20.8-30.3)$ & $72.2(64.4-78.9)$ \\
\hline Manager & $17.2(15.2-19.4)$ & $49.4(45.9-52.8)$ & $67.7(63.7-71.4)$ & $29.5(25.1-34.3)$ & $74.9(70.1-79.0)$ \\
\hline $\mathrm{p}$-value & 0.99 & $<0.0001$ & 0.5 & $<0.0001$ & 0.3 \\
\hline \multicolumn{6}{|c|}{ Parental educational attainment } \\
\hline Less than High School graduate & $16.8(14.7-19.1)$ & $43.9(39.9-48.0)$ & $68.3(65.1-71.4)$ & $24.9(20.0-30.5)$ & $73.9(67.8-79.2)$ \\
\hline High School graduate & $16.6(14.5-19.0)$ & $48.5(44.2-52.7)$ & $67.0(63.4-70.5)$ & $27.6(22.3-33.6)$ & $74.6(68.8-79.6)$ \\
\hline Some college/trade school & I8.1 (I5.3-21.3) & $48.8(44.0-53.7)$ & $65.4(60.1-70.4)$ & $29.7(23.8-36.3)$ & $78.2(71.0-84.1)$ \\
\hline College graduate & $16.6(13.5-20.1)$ & $49.7(44.5-55.0)$ & $72.3(65.9-77.9)$ & $31.9(25.5-39.0)$ & $81.8(74.1-87.5)$ \\
\hline $\mathrm{p}$-value & 0.8 & 0.01 & 0.4 & 0.003 & 0.3 \\
\hline
\end{tabular}

*Each behavior is modeled separately using hierarchical logistic regression models, specifying random intercepts for health plan and adjusting for demographics (sex, age, race or ethnicity), socioeconomic indicators (only the one specified as the table row heading), severity measures (diabetes treatment, comorbidity score, duration of diabetes), comorbidity score, depressive symptoms, and employment status.

fInsulin users only and adjusted for coverage for test strips

§ocial class defined by Olin-Wright classification

ployed; furthermore, class may be a less pertinent social determinant of health in the United States than in Europe.

The observed relationships further our understanding of the poorer health outcomes persisting in lower SES patients with diabetes in managed care settings. The strong SES gradients in smoking and physical activity are consistent with other population-based studies including diabetic patients, although the SES indicators varied across studies $[28,29]$. A population-based US study (Americans' Changing Lives Survey) reported that poor behavioral patterns failed to fully explained the greater all-cause mortality rates in lower SES individuals [30]. Although differences in model specification make the findings difficult to compare, a study of individuals from Finland, a country with socialized medicine, showed that the association between SES and mortality was practically eliminated by adjustment for health behaviors, biologic factors, and psychosocial factors [31]. Subjects with widely varying degrees of health coverage, access and quality are included in population-based studies in the U.S., while, like countries with socialized medicine, subjects in managed care settings such as in TRIAD, have relatively uniform access to care.
Mirowsky and Ross's theory of human capital [8] suggests that education improves health by allowing people to develop healthy lifestyles and prosperity (i.e., economic resources to buffer against illness and want). We found evidence that education has an independent effect on health behaviors in models adjusted for income. Moreover, education was predictive of a count of healthy behaviors, giving an indication of the degree of congruence of these health behaviors. Mirowsky and Ross's second hypothesis, the theory of personal control, suggests that education facilitates a sense of control over one's life, encouraging one to seek information that may improve health [8]. We found that education was strongly predictive of health-seeking activities in diabetes, and this was independent of income. The third theory suggests that educated parents practice and transmit a healthy lifestyle to their offspring. We found that parental education was modestly predictive of health-seeking behavior and regular exercise, although less strongly than SES indicators from mid- and later adult life.

Some study limitations and strengths should be considered. Our study analyses are based on self-reported education and health behaviors, and may be subject to some 
Table 3: Model-based* predicted probability estimates ( $95 \%$ confidence intervals) for self-reported health behaviors from multivariate models adjusting simultaneously for educational attainment and income. Translating Research Into Action (TRIAD) Study.

\begin{tabular}{|c|c|c|c|c|c|}
\hline Socioeconomic Indicator & Smoking (\%) & $\begin{array}{c}\text { Regular } \\
\text { exercise (\%) }\end{array}$ & Daily foot self-exam (\%) & $\begin{array}{l}\text { Health-seeking } \\
\text { behavior (\%) }\end{array}$ & Daily SMBG† (\%) \\
\hline \multicolumn{6}{|l|}{ Educational attainment } \\
\hline Less than High School graduate & $22.9(19.9-26.2)$ & $45.6(41.5-49.6)$ & $70.4(65.6-74.8)$ & $22.8(19.4-26.6)$ & $72.2(66.4-77.3)$ \\
\hline High School graduate & $17.3(15.4-19.3)$ & $44.2(4 I .1-47.5)$ & $65.9(62.2-69.4)$ & $25.0(22.1-28.1)$ & 76.0 (71.9-79.8) \\
\hline Some college/trade school & $18.2(16.4-20.2)$ & $48.5(45.3-51.6)$ & $68.6(65.1-72.0)$ & $31.1(28.0-34.4)$ & 75.5 (7I.5-79.1) \\
\hline College graduate & $11.0(9.2-13.1)$ & $48.3(44.7-52.0)$ & $67.7(62.7-72.2)$ & $33.3(29.7-37.1)$ & $76.3(71.1-80.8)$ \\
\hline $\mathrm{p}$-value & $<0.0001$ & 0.08 & 0.5 & $<0.0001$ & 0.7 \\
\hline \multicolumn{6}{|l|}{ Income } \\
\hline$<\$ 15 \mathrm{~K}$ & $21.1(18.2-24.3)$ & $37.2(33.5-4 I .1)$ & $69.5(65.1-73.6)$ & $24.5(21.1-28.3)$ & $74.4(69.1-79.1)$ \\
\hline$\$ 15 K-\$ 40 K$ & $18.6(16.7-20.7)$ & $45.2(42.1-48.3)$ & $68.0(64.6-71.2)$ & $28.8(25.8-32.0)$ & $76.6(72.8-80.1)$ \\
\hline$\$ 40 \mathrm{~K}-\$ 75 \mathrm{~K}$ & $15.9(13.9-18.1)$ & $50.1(46.7-53.5)$ & $68.0(63.7-72.1)$ & $29.2(26.0-32.6)$ & $71.9(66.8-76.4)$ \\
\hline$>\$ 75 \mathrm{~K}$ & $12.79(10.7-\mid 5.4)$ & $55.9(51.9-59.9)$ & $64.9(58.9-70.4)$ & $31.7(27.9-35.8)$ & $78.4(72.4-83.4)$ \\
\hline $\mathrm{P}$-value & 0.0012 & $<0.0001$ & 0.7 & 0.04 & 0.2 \\
\hline
\end{tabular}

* Each behavior is modeled separately using hierarchical logistic regression models, specifying random intercepts for health plan and adjusting for demographics (sex, age, race or ethnicity), socioeconomic indicators (only the one specified as the table row heading), severity measures (diabetes treatment, comorbidity score, duration of diabetes), comorbidity score, depressive symptoms, and employment status.

fInsulin users only and adjusted for coverage for test strips

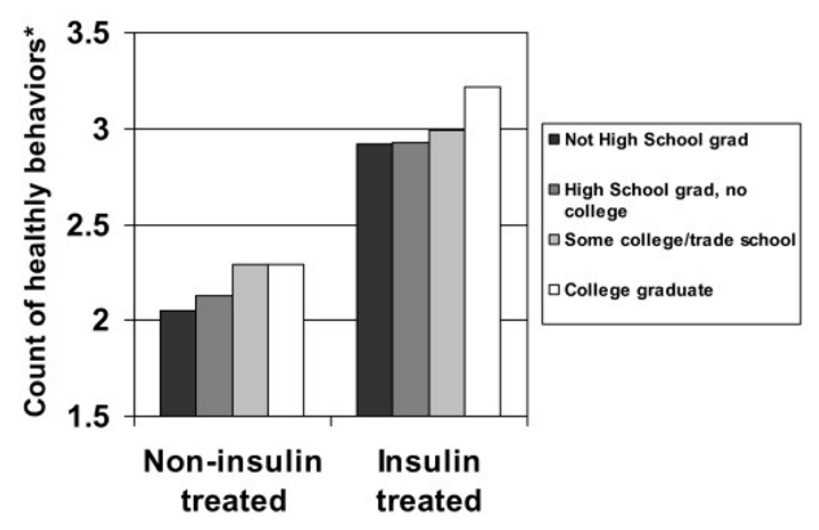

Figure I

Count of self-reported self-care behaviors* across levels of educational attainment. Translating Research Into Action for Diabetes (TRIAD) Study. *Counts by level of education were based on least square means from hierarchical regression models accounting for clustering within health plans and adjusted for sex, age, race or ethnicity, preferred language, health plan location, diabetes treatment, and the presence of comorbidities. For non-insulin treated patients, there were 4 possible self-care behaviors: I) not smoking; 2 ) regular exercise ( $\geq 10$ minutes of walking daily and/or moderate leisure time physical activity on a regular basis); 3) daily foot exam; 4) health seeking behavior (use of diabetes website, support group, health education); and a fifth for insulin-treated patients only, 5) daily self-monitoring of blood glucose. In both cases, relationships were significant $(p<0.001)$. misclassification due to social desirability of some response options. The cross-sectional design precludes causal inferences. Although we found no significant interactions, the nonlinearity of logistic regression models limits our ability to detect significant interactions [32]. The Olin Wright classification applies only to currently employed subjects and led to exclusion of approximately 200 unemployed subjects who likely had lower SES. By creating indicators and proxies for childhood (parental education), mid-life (educational attainment) and latelife (income) socioeconomic status on health outcomes, we were able to consider a "life course approach [33]." While current health behaviors may reflect early SES influences over the life course and may have an accumulated impact [34], we find that health behaviors are more strongly associated with proximate social indicators than those from early life. Unfortunately, disentangling the separate and propagated effects of early-, mid- and latelife SES was not possible [35]. Additionally, we were unable to address potential mediators (particularly health literacy [36-38]) that may explain observed social differences in behavior. Our sample came from the managed care populations participating in the 6-state TRIAD study. Findings may not apply to uninsured subjects given they would not be included in this sample. Thus our sample of subjects was not randomly selected from all people with diabetes in the United States, and our health plans may not represent the larger population of managed care settings. Our sample only included small numbers of subjects whose primary language was Spanish. It is important to note that our findings were observed in samples selected so that each examined health care behavior was unquestionably indicated as a beneficial, preventive 
measure (e.g., daily foot examination in diabetic patients with peripheral neuropathy, or a history of ulcers or amputations).

\section{Conclusion}

The need to improve health outcomes associated with diabetes has been a major focus in the United States in recent years. We find evidence of less frequent self care behaviors among particularly high risk, diabetic patients with less education and similar findings using alternative measures of socio-economic status. Our findings were consistent across demographic subgroups, and we did not find that better quality care or better health care provider communication attenuated educational disparities in health behaviors. Although the relationship between education and health behaviors was modest in strength for most behaviors, the cumulative effect of reduced practice of multiple self-care behaviors among less educated patients, over the course of diabetes, may have an important impact in shaping the social health gradient. Given the vulnerability of this population and the persistent social health disparities even in settings offering uniform care $[5,6]$, the effectiveness and benefits of targeted public health interventions that reduce barriers for and promote beneficial diabetes-related health behaviors in patients with less education should to be considered. However, because lower educational attainment is associated with poorer health, and poorer health can diminish patients' ability to practice beneficial health behaviors, we can not yet conclude from our findings that interventions aimed at improving health behaviors in disadvantaged patients will be effective in reducing social disparities in health.

\section{Abbreviations}

SES = socioeconomic status

TRIAD = Translation Research Into Action for Diabetes

SMBG = self-monitoring of blood glucose

$\mathrm{CDC}=$ Centers for Disease Control and Prevention

NIDDK = National Institute for Diabetes, Digestive Disease and Kidney Disease

CASRO = Council of American Survey Research Organizations

$\mathrm{CI}=$ confidence intervals

AJPH = American Journal of Public Health

US = United States

\section{Competing interests}

The author(s) declare that they have no competing interests.

\section{Authors' contributions}

$\mathrm{AK}, \mathrm{SE}$ and $\mathrm{AB}$ conceived, designed and coordinated the study. MS preformed the statistical analysis. $A K$ interpreted the data and drafted the manuscript. $\mathrm{AK}, \mathrm{AB}, \mathrm{DM}$, $\mathrm{WH}$ and MS obtained funding for this study. All authors were involved in primary data collection for the TRIAD study. All authors read, made critical revisions and approved the final manuscript.

\section{Acknowledgements}

This research was funded jointly through TRIAD (Program Announcement number 04005 from the Centers for Disease Control and Prevention (Division of Diabetes Translation) and the National Institutes of Health (National Institute of Diabetes and Digestive and Kidney Diseases (ROI DK065664), and the National Institute of Child Human Development (ROI HD046 I I3). It's contents are solely the responsibility of the authors and do not necessarily represent the official views of The Centers for Disease Control and Prevention, the National Institute of Diabetes and Digestive and Kidney Diseases, and National Institute of Child Human Development. Significant contributions to this study were made by members of the Translating Research into Action for Diabetes (TRIAD) Study Group. The authors acknowledge the participation of our health plan partners, TRIAD staff and participants that made this study possible. The authors acknowledge the participation of our health plan partners.

\section{References}

I. Adler NE, Ostrove JM: Socioeconomic status and health: what we know and what we don't. Ann N Y Acad Sci 1999, 896:3-I5.

2. Adler NE, Newman K: Socioeconomic disparities in health: pathways and policies. Inequality in education, income, and occupation exacerbates the gaps between the health "haves" and "have-nots". Health Aff (Millwood) 2002, 21 :60-76.

3. Bindman $A B$, Grumbach $K$, Osmond D, Komaromy M, Vranizan $K$, Lurie N, Billings J, Stewart A: Preventable hospitalizations and access to health care. JAMA 1995, 274:305-3II.

4. Goldman DP, Smith JP: Can patient self-management help explain the SES health gradient? Proc Natl Acad Sci U S A 2002, 99:10929-10934.

5. Duru OK, Mangione CM, Steers NW, Herman WH, Karter Al, Kountz D, Marrero DG, Safford MM, Waitzfelder B, Gerzoff RB, Huh $S$, Brown AF, and the TRIAD Study Group: The association between clinical care strategies and the attenuation of racial/ ethnic disparities in diabetes care: the Translating Research Into Action for Diabetes (TRIAD) Study. Med Care 2006, 44: II II-II28.

6. Brown AF, Gregg EW, Stevens MR, Karter AJ, Weinberger M, Safford MM, Gary TL, Caputo DA, Waitzfelder B, Kim C, Beckles GL: Race, ethnicity, socioeconomic position, and quality of care for adults with diabetes enrolled in managed care: the Translating Research Into Action for Diabetes (TRIAD) study. Diabetes Care 2005, 28:2864-2870.

7. Lynch JW, Kaplan GA, Salonen JT: Why do poor people behave poorly? Variation in adult health behaviours and psychosocial characteristics by stages of the socioeconomic lifecourse. Soc Sci Med 1997, 44:809-8I9.

8. Mirowsky J, Ross CE: Education, Peronal Control, Lifestyle and Health. A Human Capital Hypothesis. Research on Aging 1998, 20:415-449.

9. Al Delaimy WK, Manson JE, Solomon CG, Kawachi I, Stampfer MJ, Willett WC, Hu FB: Smoking and risk of coronary heart disease among women with type $\mathbf{2}$ diabetes mellitus. Arch Intern Med 2002, 162:273-279. 
10. Al Delaimy WK, Willett WC, Manson JE, Speizer FE, Hu FB: Smoking and mortality among women with type 2 diabetes: The Nurses' Health Study cohort. Diabetes Care 200I, 24:2043-2048.

II. Chaturvedi N, Stephenson JM, Fuller JH: The relationship between smoking and microvascular complications in the EURODIAB IDDM Complications Study. Diabetes Care 1995 | 8:785-792.

12. Chipkin SR, Klugh SA, Chasan-Taber L: Exercise and diabetes. Cardiol Clin 200I, 19:489-505.

13. Mayer-Davis EJ, D'Agostino RJ, Karter AJ, Haffner SM, Rewers MJ, Saad M, Bergman M: Intensity and amount of physical activity in relation to insulin sensitivity: the Insulin Resistance Atherosclerosis Study. JAMA 1998, 279:669-674.

14. Sarol JN Jr, Nicodemus NA Jr, Tan KM, Grava MB: Self-monitoring of blood glucose as part of a multi-component therapy among non-insulin requiring type 2 diabetes patients: a meta-analysis (1 966-2004). Curr Med Res Opin 2005, 21: I 73-184.

15. Welschen LM, Bloemendal E, Nijpels G, Dekker JM, Heine RJ, Stalman WA, Bouter LA: Self-monitoring of blood glucose in patients with type 2 diabetes who are not using insulin: a systematic review. Diabetes Care 2005, 28:15I0-15I7.

16. Chaturvedi N, Stephenson JM, Fuller JH: The relationship between socioeconomic status and diabetes control and complications in the EURODIAB IDDM Complications Study. Diabetes Care 1996, 19:423-430.

17. Kirk JK, D'Agostino RB Jr, Bell RA, Passmore LV, Bonds DE, Karter AJ, Narayan KMV: Disparities in HbAlc levels between African-American and non-Hispanic white adults with diabetes: a meta-analysis. Diabetes Care 2006, 29:2I30-2I36.

18. Chaturvedi N, Jarrett J, Shipley MJ, Fuller JH: Socioeconomic gradient in morbidity and mortality in people with diabetes: cohort study findings from the Whitehall Study and the WHO Multinational Study of Vascular Disease in Diabetes. BM] 1998, 316:100-105

19. Heisler M, Smith DM, Hayward RA, Krein SL, Kerr EA: Racial disparities in diabetes care processes, outcomes, and treatment intensity. Med Care 2003, 4I: | 221-1232.

20. Karter AJ, Ferrara A, Liu JY, Moffet HH, Ackerson LM, Selby JV: Ethnic disparities in diabetic complications in an insured population. JAMA 2002, 287:2519-2527.

21. Koskinen SV, Martelin TP, Valkonen T: Socioeconomic differences in mortality among diabetic people in Finland: five year follow up. BMJ 1996, 31 3:975-978.

22. The Translating Research Into Action for Diabetes (TRIAD) Study: A multicenter study of diabetes in managed care $\mathrm{Dia}-$ betes Care 2002, 25:386-389 [http://www.triadstudy.org]

23. Kerr EA, Gerzoff RB, Krein SL, Selby JV, Piette JD, Curb JD, Herman WH, Marrero DG, Narayan KM, Safford MM, Thompson T, Mangione CM: Diabetes care quality in the Veterans Affairs Health Care System and commercial managed care: the TRIAD study. Ann Intern Med 2004, I 4I:272-28I.

24. Wright EO: Class Counts: Comparative Studies in Class Analysis New York: Cambridge University Press; 1996.

25. Zhang J, Yu KF: What's the relative risk? A method of correcting the odds ratio in cohort studies of common outcomes. JAMA 1998, 280:1690-I69|.

26. Mangione CM, Gerzoff RB, Williamson DF, Steers WN, Kerr EA, Brown AF, Waitzfelder BE, Marrero DG, Dudley RA, Kim C, Herman $\mathrm{WH}$, Thompson TJ, Safford MM, Selby JV: The association between quality of care and the intensity of diabetes disease management programs. Ann Intern Med 2006, I45: I07-II6.

27. Karter AJ, Stevens M, Gregg E, Brown AF, Tseng C-W, Marrero DG, Duru OK, Gary T, Piette JD, Waitzfelder BE, Herman WH, Beckles GL, Safford MM, Ettner S: Educational Disparities Rates of Smoking Among Diabetic Adults: The Translating Research Into Action for Diabetes Study. Am J Public Health 2007 in press. [Epub ahead of print]

28. Oladele CR, Barnett E: Racial/Ethnic and social class differences in preventive care practices among persons with diabetes. BMC Public Health 2006, 6:259.

29. Morrato EH, Hill JO, Wyatt HR, Ghushchyan V, Sullivan PW: Physical activity in u.s. Adults with diabetes and at risk for developing diabetes, 2003. Diabetes Care 2007, 30:203-209.

30. Lantz PM, House JS, Lepkowski JM, Williams DR, Mero RP, Chen J: Socioeconomic factors, health behaviors, and mortality: results from a nationally representative prospective study of US adults. JAMA 1998, 279: 1703-I708.

31. Lynch JW, Kaplan GA, Cohen RD, Tuomilehto J, Salonen JT: Do cardiovascular risk factors explain the relation between socioeconomic status, risk of all-cause mortality, cardiovascular mortality, and acute myocardial infarction? Am J Epidemiol 1996, I44:934-942.

32. Norton EC, Wang $\mathrm{H}, \mathrm{Ai} \mathrm{C}$ : Computing interaction effects and standard errors in logit and probit models. The Stata Journal 2004, 4: 103-116.

33. Smith GD, Hart C, Blane D, Gillis C, Hawthorne V: Lifetime socioeconomic position and mortality: prospective observational study. BMJ 1997, 3 I 4:547-552.

34. Ljung R, Hallqvist J: Accumulation of adverse socioeconomic position over the entire life course and the risk of myocardial infarction among men and women: results from the Stockholm Heart Epidemiology Program (SHEEP). J Epidemiol Community Health 2006, 60: 1080-1084.

35. Hallqvist J, Lynch J, Bartley M, Lang T, Blane D: Can we disentangle life course processes of accumulation, critical period and social mobility? An analysis of disadvantaged socio-economic positions and myocardial infarction in the Stockholm Heart Epidemiology Program. Soc Sci Med 2004, 58:I555-I 562.

36. Schillinger D, Barton LR, Karter AJ, Wang F, Adler N: Does literacy mediate the relationship between education and health outcomes? A study of a low-income population with diabetes. Public Health Rep 2006, I 2 I:245-254.

37. Schillinger D, Grumbach K, Piette J, Wang F, Osmond D, Daher C, Palacios J, Sullivan GD, Bindman AB: Association of health literacy with diabetes outcomes. JAMA 2002, 288:475-482.

38. Schillinger D, Piette J, Grumbach K, Wang F, Wilson C, Daher C, Leong-Grotz K, Castro C, Bindman AB: Closing the loop: physician communication with diabetic patients who have low health literacy. Arch Intern Med 2003, 163:83-90.

\section{Pre-publication history}

The pre-publication history for this paper can be accessed here:

http://www.biomedcentral.com/1471-2458/7/308/pre pub

Publish with Biomed Central and every scientist can read your work free of charge

"BioMed Central will be the most significant development for disseminating the results of biomedical research in our lifetime. "

Sir Paul Nurse, Cancer Research UK

Your research papers will be:

- available free of charge to the entire biomedical community

- peer reviewed and published immediately upon acceptance

- cited in PubMed and archived on PubMed Central

- yours - you keep the copyright
BioMedcentral 